\title{
Learning-Oriented Assessment, Critical Thinking and English Language Speaking Skills: An Exploratory Study of Saudi EFL Learners
}

\author{
Dr. Mansoor S. Almalki \\ English Language Centre, Deanship of Supportive Studies \\ Taif University, Taif 21974, Saudi Arabia \\ E-mail: msamalki@tu.edu.sa
}

Received: March 4, $2019 \quad$ Accepted: March 19, $2019 \quad$ Published: March 21, 2019
doi:10.5296/ijele.v7i1.14528 $\quad$ URL: https://doi.org/10.5296/ijele.v7i1.14528

\begin{abstract}
This exploratory study uses the theoretical underpinnings of Learning-Oriented Assessment (LOA) to investigate Saudi EFL learners' perceptions as well as their progress in the comparative analysis of an LOA group of students and a traditional control class at Taif University English Language Centre (TUELC). The study uses both quantitative and qualitative techniques to assess how learners in the LOA group improve their English speaking proficiency during the course. The data shows that LOA proved to be a successful resource in the whole process. Answering three research questions, the study concludes that LOA may prove to be a daunting task for teachers due to their excessive monitoring responsibilities, yet it plays a vital role in improving the learners' critical thinking, their abilities for self and peer assessment and improving their overall English language skills.
\end{abstract}

Keywords: Learning-Oriented Assessment (LOA), Learner's Autonomy, Critical Thinking, Speaking Skills, English as a Foreign Language 


\section{Introduction to the Study}

Assessment and learning are interconnected and interdependent ( $\mathrm{Li} \& \mathrm{Gu}, 2018$ ). Embracing formative assessment and the broader concepts of Learning-Oriented Assessment (LOA) have been the current advancements which took place in the field of language testing (Carless 2003, 2007). What makes both formative assessment and LOA distinguished are not only their emphasis on using ways and means to exploit assessment for learning but also their very involvement of both learners' and teachers' cognitive engagement throughout the practice (Black \& William, 1998; Stiggins \& Chappuis, 2004; William \& Thompson, 2007).

In some of the Saudi EFL contexts, the learning environment is either passive or test-oriented. Most of the educational institutions in the country use summative assessment to cater for this kind of learning. In a shift from summative assessment, and in order to improve learners' performance, institutions have started moving towards formative assessment. The main reason behind this shift is the understanding of the fact that this is a viably conducive option towards improving learners' performance. Going a step ahead, Carless (2007) and Keppell, Mike and Carless (2006) argue that the further development of formative assessment is possible through the improved practicing of LOA. Emphasizing on the learning process itself, it reflects on the commonalities between formative and summative assessments. In a bid to address issues pertaining to test-oriented learning and passive learning, Carless' LOA can be further developed in a more effective manner after the variable of learner's autonomy is combined with it. Despite the fact that several studies support alternative assessment to support learning; however very few exploratory and/or comparative studies have been carried out in EFL context to validate these arguments in favor of LOA.

This is the rationale behind the current research in the EFL context of TUELC. As institutional growth depends heavily on the professionalism of university teachers (Baquerizo, Valcke \& Vanderlinde, 2018; Pitt \& Winstone, 2018), the present study deals with the LOA aspect of this overall endeavor at the TUELC, in a bid to develop an effective plan for the assessment of students' learning outcomes. Quite often teachers resist change in formal assessment methods, considering it risky (Dawson et al, 2017); however, Almalki (2014) as serts that a productive and efficient assessment design can be ensured through an ongoing revision of policies at the institutional level.

Since using assessment as learning has been the hallmark of learning oriented assessment (Ashegh, 2018), keeping in view the available literature as well as the contextual variables, the purpose of this study is to use the theoretical underpinnings of LOA to validate the oft-quoted arguments in favor of alternative assessments. The further organizational development of the study is based on the following sections:

Section 2 caters for ' $L O A$ in Brief'.

Section 3 states the 'Research Questions'.

Section 4 deals with the 'Research Design'.

Section 5 describes 'Data Analysis, Results and Discussion'.

Section 6 presents the 'Conclusion and Recommendations'. 


\section{LOA in Brief}

Originating from Carless' researches (2006; 2007), LOA has mostly been hailed as emphasizing on not only the facilitation of learning but also authenticating the achievements (Carless, 2007). Terming LOA as the overlapping of summative and formative assessment, Carless (2007) stresses that the former provides for the certification of learning while the latter for its very promotion. Carless et al. (2006) detail the traits of effective learning-oriented assessments in these words:

(1) Effective learning may be ensured through tasks which stimulate learning; (2) performance evaluation is done in a way that learners not only do their own evaluation but also of their peers; (3) students receive their feedback on time, telling them about the problems as well as ways to improve on their performance. Despite the fact that all the aforementioned LOA traits are equally pertinent, the stress on the implied deep and implicit learning is foregrounded due to its capacity to enable learners for long term learning. Unlike the surface learning where learners may mechanically memorize things, resulting in bursts lasting for a short period of time, LOA aims for a deeper learning (Carless, 2007).

Despite the fact that researchers such as Coates (2014) emphasize the recent influx in the importance of learning outcome, the fact remains that the mostly Global-North-centric development and basis of assessment packages as well as their related theoretical underpinnings, if applied in any other context, need to be tested and validated before declaring them the mostly-exclusive touchstone for assessing learners' performance. Authentic assessment means problematizing, contextualizing and bringing in realism in the process of assessing curricular content (Benner et al., 2009; Raymond et al., 2013). The current study is a step ahead in that direction, aiming at developing a contextually-viable mechanism for LOA in the TUELC context.

\section{Research Questions}

This study aims to find answers to the following questions:

(1) What are the obstacles perceived by EFL learners when implementing LOA?

(2) How much impact LOA has on learners' autonomy?

(3) To what extent is LOA effective in the EFL context?

\section{Research Design}

For the comparative analysis, two classes are selected: a control class and an experimental one. All the students who participated in the courses are second semester students with non-English major. They are all males, in their late teens. For the study, they are taught EUSE Book 2 of Cambridge University Press. The number of students in both the classes is 48 in the control class and 45 in the experimental one. 


\section{Macrothink}

The same learning material and teaching method have been used for both classes. The only difference is that the traditional way of organizing the class has been used in the control class, where the assessment criteria as well as the learning objectives have been determined by the teachers. For the evaluation of the course, the teacher prepares the final examination. On the other hand, the following six-step procedure is carried out in the experimental class.

\section{LOA Training}

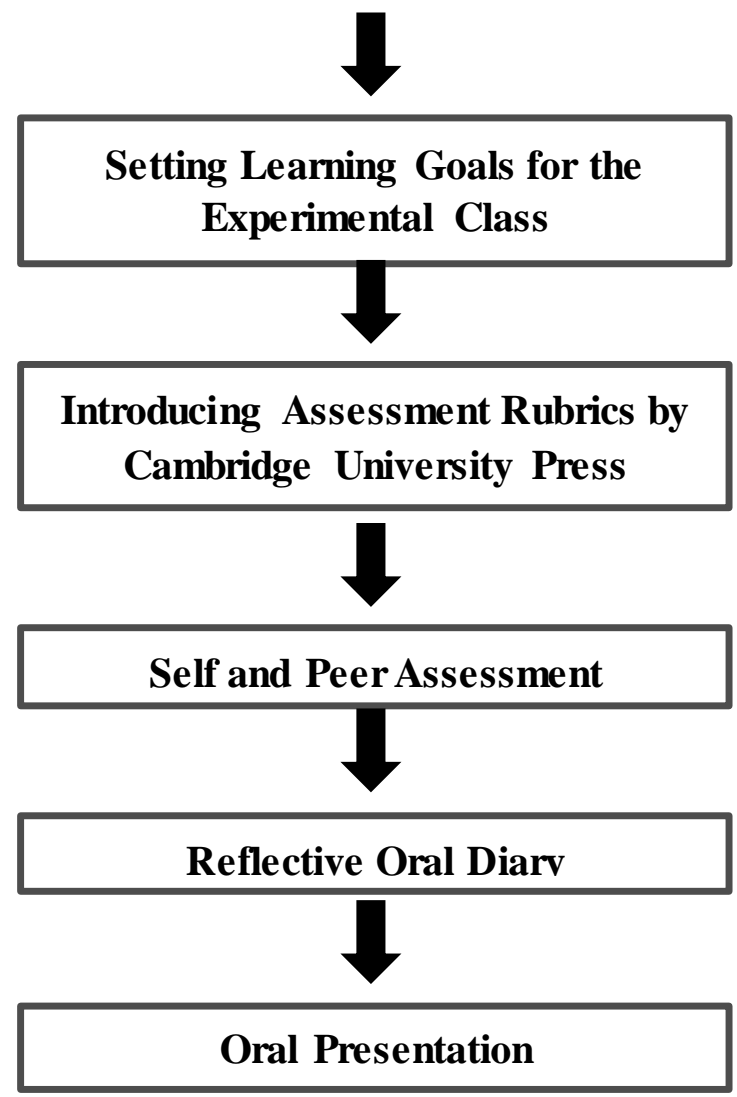

First Stage - LOA Training: At this stage, a short training course on LOA is arranged for the learners who are part of the experimental class; however, the traditional one proceeds without any such arrangement. A number of studies dealing with the Asian learners' experience of alternative assessments show that they usually face problems in matters like portfolio assessment mainly due to their lack of experience in it (Lo, 2010; Yang, 2003). This is the rationale behind the LOA training for the learners of the experimental class. In order to see the impact and usefulness of the LOA training some open questions were also asked from the learners, first, at the start of the training and, then, at the end of the training sessions. Their responses proved that the training improved their LOA-related knowledge, whereas the pre-training responses showed that they did not have any knowledge of what LOA is and how it works. 
Second Stage - Setting Learning Goals: As described earlier that the control class is told about the assessment criteria and learning objectives by the teacher, who is the decision maker for all affairs. To start this process of establishing the learning goals for the experimental class, the learners are asked to, first, write down those learning goals which they are expecting of the course. After this, the teacher suggests his/her learning goals for the course. As the teacher works as a facilitator, s/he asks learners to carefully compare the learning goals offered by the teacher and the ones suggested by the learners in a bid to promote their intendent thinking and reach a well-thought out set of learning goals for the course. This is followed by a discussion among the learners towards finalizing the learning goals for the course to be studied. The three course objectives which are finalized are as follows:

(1) To improve learners' speaking fluency; (2) to improve their linguistic competence as well as strategic competence; (3) to Expand their worldview.

Third Stage - Introducing Assessment Rubrics by Cambridge University Press: It caters for the preparation that the teacher does before the teaching starts. Here, the assessment rubrics by Cambrid ge University Press (2012) are shared with the learners. The teacher also prepares the learning materials as well as the complete teaching plan for the course.

Fourth Stage - Self and Peer Assessment by Learners: As Black and William (1998) declare self-assessment as one of the offshoots of alternative assessment, Moqbel (2018) highlights the pedagogical ad vantages of its use. As far as the assessment criteria are concerned, the role of the teacher in experimental class is to facilitate its establishment. The experimental class uses the aforementioned CUP assessment criteria to gauge the achievement of learning goals through self-assessment. The way it was done for this class was that the teacher asked the learners to speak up how they perceive that they should be assessed for the course. This was, then, followed by a class discussion among the learners to ascertain the ways and means on their assessment. The role of the teacher is this whole discussion is to guide the learners to concentrate on the learning process rather than staying concerned with the learning product all along. As a result of the discussion by the learners and the role of the teacher, the following assessment criteria have been established: The following table shows the list of four assignments which the learners will be required to complete. Regarding assessment criteria for EFL learners' speaking ability, the assessment rubrics by Cambridge University Press (CUP) have been adopted to take help from in all the assessments. In a bid to make every bit of the assessment criteria clear to the learners for their better comprehension and understanding, the teacher in the experimental class explains everything in detail.

Assessment Criteria

\begin{tabular}{|l|l|l|}
\hline Assignment 1 & $20 \%$ & Listen to a news bulletin and answer oral questions at the end \\
\hline Assignment 2 & $35 \%$ & Assessing the Self and Peers for Speaking Skills \\
\hline Assignment 3 & $20 \%$ & Reflective Speaking Discussion \\
\hline Assignment 4 & $25 \%$ & Oral Presentation \\
\hline
\end{tabular}


Fifth Stage - Reflective Oral Diary: While studying the Module, it is the responsibility of the teacher to not only organize learning but also monitor it throughout the course period. Week 1 is dedicated by the teacher for class discussions. Weeks 2 and 3 are spent by the teacher to develop the learners' ability to speak in English on a given topic. Week 4 caters for the learners' views on the topic of diversity through a thorough brainstorming activity. Weeks 5 and 6 are dedicated to ask learners to prepare three oral scrips of a substantial length. During these two weeks, the learners are also required to see and discuss the overall shape of the scripts with their class fellows. This is followed by finding out three basic structures that are used to develop long speeches. The activity is facilitated by the teacher throughout. The three structures are: (1) pros and cons in opinions; (2) Asking questions; and (3) Establishing causal relationship between events and issues. At the end of the activity, the learners are required to recapitulate and summarize what they learnt during the two weeks.

Assignment 1 for the course deals with collecting information from a news bulletin to deliver a long speech. They may give examples as part of the assignment. Weeks 7 and 8 cater for developing the learners' textual knowledge of spoken English such as organization and cohesion. These two weeks also include working on the grammatical knowled ge of the learners. These goals are achieved through activities such as one-minute speaking and retelling stories. Weeks 9, 10, 11 and 12 are used by the learners to improve their functional knowledge of illocutionary competence by discussion a number of hot topics.

These discussion topics also include reviewing the knowledge that they have already gained in the course over the past weeks. The teacher divides the learners in groups. S/he encourages them to talk to their group members and ensure giving presentation on topics of interest. The teacher also makes sure that the learners record these presentations by other learners to carry out peer and self-assessment. S/he helps the learners in effectively carrying out the peer and self-assessment of the recorded speeches by interacting with them while they identify their strengths and weaknesses in the speeches. This is the point where the teacher offers productive feedback on tasks. Moreover, the teacher assesses the speeches in a bid to draw a comparison with the peer and self-assessment done by the experimental class learners. In order to foster the autonomy of the learners, the teacher and the learners analyze the variations among the responses given through the assessment provided by the teacher, peer and self. Week 12 is reserved for the learners to select one of the already discussed topics and give a presentation on its related individual peer assessment and self-assessment. This presentation serves as the Assignment 2 for the course.

Weeks 13-15 witness the learners enhance their speaking strategies of planning, appraising and goal setting through three tasks, namely debating, role playing and public speaking. Week 16 is the final examination week that consists of a long oral presentation.

Sixth Stage - Oral Presentation: Unlike the traditional way of testing that has been applied in the control class for the study, the experimental class adopts the learning evaluation that is in itself learning-oriented. As outlined in the aforementioned table, the learning evaluation for the experimental class consists of four assignments. 
The first assignment (20\%), which is in week 4 of the course, asks for an oral recap of a news bulletin that shows how much the learner understands developing a speech. The second assignment $(35 \%)$ that falls in week 12 developing the self and peer observation techniques of the learners, their performance in self-assessment (15\%), and their efficiency in assessing their peers $(20 \%)$. As part of the group's assignment $3(20 \%)$, their critical thinking skills are assessed as they will weekly summarize of their learning in the form of a reflective speaking discussion. The teacher provides feedback, every week, on the learners' reflective journal, thus monitoring their learning throughout the course. As the final week of the course is reserved for assignment $4(25 \%)$ that is the final examination, the learners are required to give oral presentation on a topic.

\subsection{Instruments}

In a bid to see the impact of LOA on the experimental class, the data was collected through interviewing the learners and with the help of the teacher's diaries. Throughout the observation process, the teacher has been taking notes regarding any issues or problem which they learners may have faced during the Module. This qualitative data serves as a direct evidence towards the overall findings and/or conclusion of the study.

\section{Data Analysis, Results and Discussion}

In a bid to see the impact of LOA on the experimental class, the data was collected through pre and post-tests and analyzed quantitatively. Moreover interviews of the learners were also held and augmented with the help of the teacher's diaries. Throughout the observation process, the teacher has been taking notes regarding any issues or problem which they learners may have faced during the Module. This qualitative data serves as direct evidence towards the overall findings and/or conclusion of the study. The results as well as the related discussion, based on the findings of the study, are given below:

\subsection{Learners' English Speaking Ability in Pre-Tests of Control and Experimental Groups}

In a bid to see the English speaking skills learners in both groups, an independent-sample t-test was carried out. It includes T-test and Levene's test to see the performance of the learners in their test on speaking. Tables 1 and 2 show the related data.

Equal Variances have been shown in Table 1 to suggest that the English speaking ability of the all the learners is almost the same. As shown in Table 2, there was no major gap between among learners of the two groups i.e learners in the control/traditional group stand at $(\mathrm{M}=$ 82.437, $\mathrm{SD}=15.373)$, while experimental ones at $(\mathrm{M}=81.327, \mathrm{SD}=12.737)$. This shows that all the learners in both the groups are at the same spoken proficiency level. Hence, as the homogeneity of the learners in terms of their English language proficiency is ascertained, providing the level ground for the both groups to start the teaching. 
Table 1. Oral Pretest -- Establishing Equality of Variances Through Levene's Test

\begin{tabular}{|l|l|l|}
\hline Equality of Variances & F & Sig. \\
\hline Experimental and Control Groups Difference & 3.035 & $0.070^{*}$ \\
\hline
\end{tabular}

*Alpha Level: 0.01

Table 2. Comparison of Experimental and Control Classes

\begin{tabular}{|l|l|l|l|l|l|l|l|}
\hline & Mean & Number & $\begin{array}{l}\text { Standard } \\
\text { deviation }\end{array}$ & $\begin{array}{l}\text { Standard } \\
\text { error mean }\end{array}$ & $\mathrm{T}$ & Difference & $\begin{array}{l}\text { Tow-tailed } \\
\text { sig. }\end{array}$ \\
\hline Experimental & 81.327 & 45 & 12.737 & 1.721 & & & \\
\hline Control & 82.437 & 48 & 15.373 & 1.979 & & & \\
\hline Difference & -1.110 & & -2.636 & & -0.561 & 102 & $0.576^{*}$ \\
\hline
\end{tabular}

*Alpha Level: 0.01

\subsection{Speaking Skills of Control and Experimental Class Learners in Post-Test}

In order to see the impact of teaching on the oral English proficiency level of learners in both control and experimental classes, a post test within all the learners in both groups was conducted. Since these two different groups, taught in two different way, a comparison of their post-teaching language proficiency needed to see. For that, Levene's test and an independent-sample t-test were conducted. Results are given below:

Table 3. Oral Post-Test -- Equality of Variance Through Levene's Test

\begin{tabular}{|l|l|l|}
\hline Equality of Variances & F & Sig. \\
\hline Experimental and Control Groups Variations & 9.635 & $0.003^{*}$ \\
\hline
\end{tabular}

*Alpha Level: 0.05

Table 4. Oral Post-Test -- Equality of Means

\begin{tabular}{|l|l|l|l|l|l|l|l|}
\hline & Mean & $\mathrm{N}$ & $\begin{array}{l}\text { Standard } \\
\text { deviation }\end{array}$ & $\begin{array}{l}\text { Standard } \\
\text { Error Mean }\end{array}$ & $\mathrm{T}$ & Difference & $\begin{array}{l}\text { Two-tailed } \\
\text { sig. }\end{array}$ \\
\hline Experimental & 92.726 & 45 & 13.958 & 1.322 & & & \\
\hline Control & 80.898 & 48 & 19.587 & 2.785 & & & \\
\hline $\begin{array}{l}\text { Class } \\
\text { Difference }\end{array}$ & 11.828 & & 5.629 & & 1.9987 & 98 & $0.022^{*}$ \\
\hline
\end{tabular}

*Alpha Level: 0.05

Detailed above, there has been a difference of Variance between the control and experimental group. This is the reason why this unequal Variance was kept in consideration while the 


\section{Macrothink}

following t-test was carried out. The resultant Table 5 is quite significant to show the difference between the performances of learners in both classes. The difference in the speaking skills of both the groups speaks a lot of the performance of learners in both groups. Hence, the data confirms that the performance of learners in the experimental group has been far better than the performance of learners in the control group. Moreover, the fact that LOA has the capacity to close the gap among individual differences has also been proved through the less standard deviation in the experimental group, compared to the one in the control one.

\subsection{Comparison of Speaking Skills in Experimental Class}

Table 5 shows a summary of the learners' performance in their tests. This shows the performance of the experimental class learners in their proficiency in Speaking English:

It shows that there has been a remarkable change in the learners' performance in their pre- test and post-test, showing their improvement. It shows how LOA based teaching has helped the learners to improve their English speaking skills and the improvement is pretty visible.

Table 5. Performance of Experimental Class in Oral Tests -- Paired-Samples Test

\begin{tabular}{|l|l|l|l|l|l|l|l|}
\hline & Mean & Number & $\begin{array}{l}\text { Standard } \\
\text { Deviation }\end{array}$ & $\begin{array}{l}\text { Standard } \\
\text { error Mean }\end{array}$ & T & Difference & $\begin{array}{l}\text { Two-tailed } \\
\text { sig. }\end{array}$ \\
\hline Pre-test & 81.327 & 45 & 11.737 & 1.565 & & & \\
\hline Post-test & 92.726 & 45 & 12.962 & 1.721 & & & \\
\hline $\begin{array}{l}\text { Paired } \\
\text { Difference }\end{array}$ & -11.399 & & 4.480 & & -7.186 & 50 & $0.000^{*}$ \\
\hline
\end{tabular}

*Alpha Level: 0.05

\subsection{Comparison of Speaking Skills in Control Class}

Table 6 shows the paired t-Test results below to highlight the performance of the control class learners in their pre-test and post-test. There has been a significant difference between the pre-test and post-test results as shown above. This demonstrates that the oral proficiency control class learners has not improved considerably over the course of the teaching.

Table 6. Performance of Experimental Class in Oral Tests -- Paired-Samples Test

\begin{tabular}{|l|l|l|l|l|l|l|l|}
\hline & Mean & Number & $\begin{array}{l}\text { Standard } \\
\text { deviation }\end{array}$ & $\begin{array}{l}\text { Standard } \\
\text { Error Mean }\end{array}$ & T & difference & $\begin{array}{l}\text { Two-tailed } \\
\text { sig }\end{array}$ \\
\hline Pre-test & 82.437 & 48 & 12.368 & 1.636 & & & \\
\hline Post-test & 80.898 & 48 & 14.458 & 2.452 & & & \\
\hline $\begin{array}{l}\text { Paired } \\
\text { Difference }\end{array}$ & -1.493 & & 4.480 & & -2.410 & 52 & $0.020^{*}$ \\
\hline
\end{tabular}

*Alpha Level: 0.05 


\subsection{Teaching Diaries and Interviews}

Interviews were conducted with all the learners who participated in the course. In a bid to bring forth the merits and demerits of LOA, questions from all the learners were welcomed. Their comments on LOA with respect to their learning during the course were encouraged. These responses were also triangulated for authenticity through the teacher's notes which he recorded as his daily diaries. These notes by the teacher served as a record of his reflections on the learners' learning as well as any challenges that they faced during this period. The details the findings based on the interviews as well teaching diaries are as follows:

Responding to the question 'What are your impressions of LOA? Most learners during the interviews appreciated LOA for boosting their confidence and self-esteem, relaxing them in time when they were nervous. They argued that their desire and motivation to learn has been drastically increased. They hailed LOA for enhancing their learning autonomy, saying that there have been positive effects of the course in terms of its affective adjustment. They said that the process of learning was made more enjoyable throughout the course.

Most of the learners give credit to LOA for enabling them develop the capacity of reflecting on issues and write in a more critical manner, terming it as an extra gain from the course. While checking the teaching diaries, this point was quite emphatically mentioned that the learners developed their capacity from ineffective reflection to productive reflection over the course of the experimental language course. The teaching diary says that most of the learners failed to write on the effective reflective journal during the first two weeks of the course, as some of the students were able to only mention their class performance in their write-ups. Some of them could only mention certain notes from their classroom activities.

Some were able only to describe their teacher in the class. Some of the students would detach their writing from their course contents and would write about their overall university life. The teaching diaries noted that these failures on part of the learners were mainly due to insufficient guidance on the task. Instead of letting it go like this, this issue is then taken care of by the teacher through reflective journal. The sample carries not only related critical thinking skills but also their weaknesses and strengths in learning. Other than providing the learners with the sample, the teacher's feedback was tailored in a way that it becomes more evaluative rather than mere descriptive in its essence.

Despite the fact that it is not easy to inculcate the ability for critical thinking among these learners due to several cultural phenomena mainly the decades long teacher-centered approach towards teaching in most of parts of Saudi Arabia, these goals can be achieved through consistent encouragement, creative thinking, independent practice and sustained guidance in a setting like this one. As a result, it was witnessed that the end of the course reflective journals by the learners carried critical thinking and self-disciplining in the form of their analysis of learning weaknesses. They also gave further consideration to the topic in the form of discussion during the class, questioning the teacher's suggestions, commenting on the course design and progressions, and making inquiries about learning speaking for the future. This is how their independent thinking and critical approach towards matters was cultivated through using reflective journals to link formative assessment to autonomous assessment during the course. 
When asked in the interviews, 'Did you find any problems with LOA over the period in your course? The learners revealed that their burden of learning increased a great deal during the course. They said that they had to spend a lot of time on peer assessment too. In order to authenticate this issue, a perusal of the teaching diaries was carried out which showed that teacher had to cope with an enormous amount of work, proving as the biggest challenge throughout the LOA practice in the course. The notes in the diaries observed that long range of the teacher's responsibilities included checking all the learners' weekly reflective journal, providing detailed feedback to every learner and carrying out a detailed analysis of the difference between his own assessment of the learners' work and the learners' self and peer assessment. The diaries suggest that there should be a substantial decrease in the teaching content in a bid to spare maximum time for the teacher's feedback, adding that there is a need to increase peer assessment, so that the teacher's work can be brought to a manageable level. [5]. Keeping in view the progress of the students, their level of satisfaction as well as their overall achievements in terms of the linguistic and critical thinks domains, a decrease in the teaching content may facilitate teachers but will negatively impact the prospective achievements of the learners. Instead of decreasing the teaching content to facilita te the teacher, we may decrease the number of courses that a particular teacher is teaching. This will provide enough time to the teacher to implement the LOA related nitty gritty of the practice. Among the long-term solutions to this matter, there is a need to advance educational technology to share some part of the teachers' job.

The learners' interview showed that although the learners were involved through LOA in the whole learning process; however, learners in some of the cases continue repeating their mistakes. They, instead, put the burden of their shortcomings and mistakes on insufficient feedback by the teacher. Their repetitive mistakes were found in their weekly reflective journals as well. Other than insufficient feedback by the teacher, some of the possible reasons may be learners' over-dependence on the teacher's feedback, possible frustration among learners due to an excessive amount of work and the fact that it is a slow process to improve one's language proficiency.

\section{Conclusion and Recommendations}

Using the theoretical underpinnings of LOA, this exploratory study peeps into how both current and future class's learners can be taught to facilitate their process of language learning. Set in the EFL context at Taif University English Language Centre, the study endeavors to find answers to three research questions, mainly dealing with improving the English speaking ability of learners through the implementation of LOA, and recording any issues or problems that are faced by both learners as the teacher during this process.

The study shows that autonomy of the learners may be brought about through proper processes and this would be in line with the theoretical background of LOA, provided by Carless (2007).The study finds that instead of dealing with assessment as the binary of summative and formative assessment, more factors such as the learner's autonomy, workload and respect may be add value to such studies. For the three research questions, the study provides the following 
insights :

To answer the first research question, the study shows that there was no difference between the language proficiency of both the control class and the experimental class at the beginning of the study. The pre-tests for both group stands witness to the equal language proficiency of both groups. However, the post-tests as well as the interviews show that experimental class learners were significantly improved compared to the learners in the control class, proving the point that the LOA-based approach has been more effective in improving the speaking ability of EFL learners. After the course, the greater progress

For the second research question, the study finds that most of the learners found LOA as a great help in their learning. Not only their post-tests but also their interviews prove the point that they found LOA improving the learners' autonomy in not only planning the course but also carrying it forward. LOA has also been helpful in improving their critical thinking skills, which are not possible in the control class.

Regarding the third research question, the study finds the following problems in the implementation of LOA in the EFL context: (1) Time management has been one of the problems; (1) some of the learners complained about the increased work load for both teachers and learners; (3) For some of the learners, the time that they took in overcoming their mistakes was way too long; (4) over the first two weeks, the practice of reflective learning failed. Keeping in view the progress of the students, their level of satisfaction as well as their overall achievements in terms of the linguistic and critical thinks domains, a decrease in the teaching content may facilitate teachers but will negatively impact the prospective achievements of the learners. Instead of decreasing the teaching content to facilitate the teacher, we may decrease the number of courses that a particular teacher is teaching. This will provide enough time to the teacher to implement the LOA related nitty gritty of the practice. Among the long-term solutions to this matter, there is a need to advance educational technology to share some part of the teachers' job and encourage autonomous assessment.

As the length of the study is limited, it is recommended that further studies may be carried out to further research not only LOA in an EFL context but over a longer period of time.

\section{References}

Almalki, M. (2014). A preliminary design framework for formative blended assessments in tertiary English as a foreign language (EFL) programs: an exploratory study in Saudi Arabia (Doctoral dissertation). Retrieved from The University of Melbourne library. https://minerva-access.unimelb.edu.au/handle/11343/40895

Ashegh, L., N. (2018). The effect of learning-oriented assessment on learning pronunciation among Iranian EFL learners. International Journal of Education and Literacy Studies, 6(2), 63-68.

Baquerizo, J., C, Valcke, M., \& Vanderlinde, C. (2018). Professional development initiatives 
for university teachers: Variables that influence the transfer of learning to the workplace, Innovations in Education and Teaching International. https://doi.org/10.1080/14703297.2018.1479283

Benner, P., M. Sutphen, V. Leonard, \& L. Day. (2009). Educating Nurses: A Call for Radical Transformation. San Francisco, JA: Jossey-Bass. https://doi.org/10.3928/01484834-20120402-01

Black, P., \& William, D. (1998). Assessment and classroom learning. Assessment in Education, 5(1), 7-74.

Carless, D. (2007). Learning-oriented assessment: conceptual bases and practical implications. Innovations in Education and Teaching International, 44(1), 57-66.

Dawson, P., D. Boud, J. Tai, R. Ajjawi \& E. Panadero (2017). Building Courses to Develop 'Evaluativ Judgement': Learning to Make Decisions about Quality Work. Assessment in Higher Education conference. Manchester, UK, June.

Keppell, M., \& Carless, D. (2006). Learning-oriented assessment: a technology-based case study. Assessment in Education, 13(2), 179-191.

Lo, Y. (2010). mplementing reflective portfolios for promoting autonomous learning among EFL college students in Taiwan. Language Teaching Research, 14(1), 77-95.

Liu, Q., \& Wang, L. (2010). The feasibility of applying portfolio assessment in oral English courses for Chinese tertiary learners (Chinese version: Zhong Guo Da Xue Sheng Kou Yu Neng Li Dang An Dai Ping Jia Ke Xing Xing Yan Jiu), Foreign Language and Their Teaching, $6,42-55$.

Moqbel, Marwan Saeed Saif (2018). "Self-assessment in EFL Grammar Classroom: A Study of EFL Learners at the Centre for Languages and Translation, Ibb University," International Journal for Research in Education: Vol. 42: Iss. 2, Article 9. Available at: https://scholarworks. uaeu.ac.ae/ijre/vo142/iss2/9

Pitt, E., \& Winstone, N. (2018). The impact of anonymous marking on students' perceptions of fairness, feedback and relationships with lecturers. Assessment \& Evaluation in Higher Education, 43(7), 1183-1193. https//doi.org/10.1080/02602938.2018.1437594.

Raymond, J., C. Homer, R. Smith, \& J. Gray. (2013). Learning through Authentic Assessment. An Evaluation of a New Development in the Undergraduate Midwifery Curriculum. Nurse Education in Practice, 13(5), 471-476. https://doi.org/10.1016/j.nepr.2012.10.006.

Stiggins, R. J., \& Chappuis, J. (2006). What a difference a word makes: Assessment for learning rather than assessment OF learning helps students succeed. Journal of Staff Development, 27(1), 10-14.

Yang, N. (2003). Inte grating portfolios into learning strategy-based instruction for EFL college students. International Review of Applied Linguistics in Language Teaching, 41, 293-317. 


\section{Macrothink}

International Journal of English Language Education

ISSN 2325-0887

2019, Vol. 7, No. 1

Yulong Li, \& Xiangdong Gu. (2018). Learning oriented assessment: A systemic approach. Innovations in Education and Teaching International, 55(4), 497-498. https://doi.org/10.1080/14703297.2018.1480254

\section{Copyright Disclaimer}

Copyright for this article is retained by the author(s), with first publication rights granted to the journal.

This is an open-access article distributed under the terms and conditions of the Creative Commons Attribution license (http://creativecommons.org/licenses/by/3.0/). 